\title{
Guest Editor Notes
}

\author{
Troy Harden
}

Published online: 6 January 2015

(c) Springer Science+Business Media New York 2015

\section{Introduction to Special Issue}

Community violence that impacts the lives of children, adolescents and their families can take place in many forms. Developing creative and effective methods to address this violence is a topic of interest for Social Work practitioners and researchers. This special issue includes studies presenting models and empirical research that support various approaches to addressing risk factors, particularly, but not limited to, those associated with violence. The need for, and development of, innovative practices are highlighted, including those that are traumainformed and culturally relevant.

\section{Establishing the Need for Innovation}

In establishing the need for these types of models, Chen, Propp and Lee's research concerning youth exposed to violence and the lack of civic engagement, explores the importance of the loss of citizenship among young people who are impacted by violence. As communities lose important voices and actors, methods to build social capital are needed. Samuel, in researching the utilization of mental health services for African American male adolescents involved within the juvenile justice system, exposes a widely held belief that there is a high level of stigma attached to traditional mental health services. This author suggests that interventions that limit stigma and include strategies around social networks are needed, particularly

T. Harden $(\bowtie)$

Department of Social Work, Chicago State University, 9501 S.

King Drive, Chicago, IL 60628, USA

e-mail: tharden@csu.edu in the face of growing evidence associated with such mental health challenges as PTSD and depression.

\section{Promising Practices}

Harden, Kenemore, Mann, Edwards, Martinson and List's innovative project explores the need to move beyond programs that do something for young people, to programs that engage youth to do something with them. This fundamental shift is at the core of positive youth development, and offers promise concerning civic participation and trauma-informed practices. In a similar vein demonstrating the importance of cultural affirmation in programming, Watson explores the importance of culturally-appropriate work with African American males, including the need for rites of passage programs as a method to address social problems. Vincent, McCormak and Johnson discuss a model for families impacted by loss due to homicide, detailing the need for comprehensive services that move beyond case management and counseling, to explore advocacy and system-wide support for these families. Harley and Hunn explore a theory of hope, in reporting African America adolescent experiences with faith and hope, demonstrating their importance through the use of photo voice. Absent in much of the trauma-informed literature is the importance of spirituality and faith practices, particularly among African Americans, and utilizing photo voice combines an innovative intervention to enhance spiritual resilience. Waecther and Wekerle, in reviewing the literature concerning interventions that utilized "Eastern Arts", contribute an important scan of the evidence related to trauma and the growing interest in mindfulness practices as a way to address child maltreatment. Their article demonstrates the need for further examination of 
these types of interventions. All of these models and interventions move beyond traditional interventions in order to build affirmative outcomes for youth and families.

This issue promises to add to the growing importance of establishing trauma-informed practices that move beyond traditional therapeutic models, and push the boundaries of work with children, adolescents and their families to include innovative, evidence-based strategies that strengthen and build communities. 